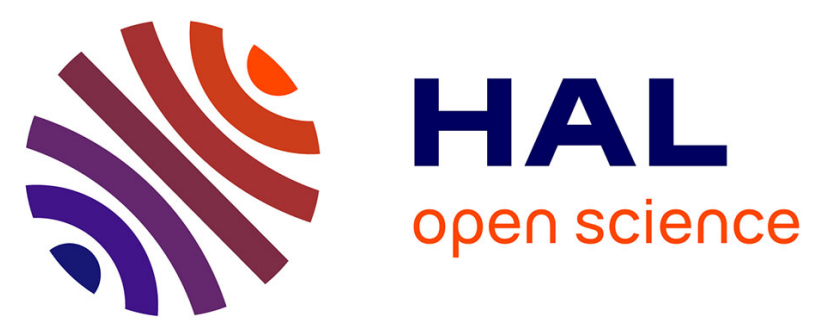

\title{
Novel lipid-based quaternary ammonium sophorolipid amphiphiles with antimicrobial and transfection activities
}

Elisabeth I.P. Delbeke, Jonas Everaert, Olivier Lozach, Tony Le Gall, Mathieu Berchel, Tristan Montier, Paul-Alain Jaffres, Petra Rigole, Tom Coenye, Martha Brennich, et al.

\section{To cite this version:}

Elisabeth I.P. Delbeke, Jonas Everaert, Olivier Lozach, Tony Le Gall, Mathieu Berchel, et al.. Novel lipid-based quaternary ammonium sophorolipid amphiphiles with antimicrobial and transfection activities. ChemSusChem, 2019, 12 (15), pp.3642-3653. 10.1002/cssc.201900721 . hal-02129348

\section{HAL Id: hal-02129348 \\ https://hal.sorbonne-universite.fr/hal-02129348}

Submitted on 16 Feb 2021

HAL is a multi-disciplinary open access archive for the deposit and dissemination of scientific research documents, whether they are published or not. The documents may come from teaching and research institutions in France or abroad, or from public or private research centers.
L'archive ouverte pluridisciplinaire HAL, est destinée au dépôt et à la diffusion de documents scientifiques de niveau recherche, publiés ou non, émanant des établissements d'enseignement et de recherche français ou étrangers, des laboratoires publics ou privés. 


\title{
Lipid-Based Quaternary Ammonium Sophorolipid Amphiphiles with Antimicrobial and Transfection Activities
}

\author{
Elisabeth I. P. Delbeke, ${ }^{[a, b]}$ Jonas Everaert, ${ }^{[a, c]}$ Olivier Lozach, ${ }^{[d]}$ Tony Le Gall, ${ }^{[e, f]}$ \\ Mathieu Berchel, ${ }^{[d, e]}$ Tristan Montier, ${ }^{[\mathrm{e}, \mathrm{f}, \mathrm{g}, \mathrm{h}]}$ Paul-Alain Jaffrès, ${ }^{[\mathrm{d}, \mathrm{e}]}$ Petra Rigole, ${ }^{[\mathrm{i}]}$ Tom Coenye, ${ }^{[\mathrm{p}}$ \\ Martha Brennich, ${ }^{[j, k]}$ Niki Baccile, ${ }^{[l]}$ Sophie L. K. W. Roelants, ${ }^{[c, m]}$ Wim Soetaert, ${ }^{[c, m]}$ \\ Inge N. A. Van Bogaert, ${ }^{[\mathrm{n}]}$ Kevin M. Van Geem, ${ }^{[b]}$ and Christian V. Stevens ${ }^{*[a]}$
}

\begin{abstract}
Twelve new quaternary ammonium sophorolipids with long alkyl chains on the nitrogen atom were synthesized starting from oleic and petroselinic acid-based sophorolipids. These novel derivatives were evaluated for their antimicrobial activity against selected Gram-negative and Gram-positive bacteria and their transfection efficacies on three different eukaryotic cell lines in vitro as good activities were demonstrated for previously synthesized derivatives. Self-assembly properties were also evaluated. All compounds proved to possess antimicrobial
\end{abstract}

and transfection properties, and trends could be observed based on the length of the nitrogen substituent and the total length of the sophorolipid tail. Moreover, all long-chain quaternary ammonium sophorolipids form micelles, which proved to be a prerequisite to induce antimicrobial activity and transfection capacity. These results are promising for future healthcare applications of long-chained quaternary ammonium sophorolipids.

\section{Introduction}

In the last few decades, the transition towards a bio-based economy has been initiated. This transition focuses on the use of renewable resources and sustainable technologies as replacements for the classical, fossil-based derivatives. ${ }^{[1]}$ At present, only $8 \%$ of all the chemicals produced in Europe are based on renewable resources. ${ }^{[2]}$ Although the application of renewable resources is not a new concept, this mostly com- prises the use of simple resources or unpurified products giving access to low-added-value products. The application of renewable resources in high-added-value products, often having a complex structure, faces much more challenges as multiple reaction steps are needed to obtain the desired products. Owing to mostly a higher price of renewable based chemicals, they can hardly compete with fossil-based products. [a] Dr. E. I. P. Delbeke, J. Everaert, Prof. C. V. Steven

SynBioC, Department of Green Chemistry and Technology

Ghent University, Coupure Links 653, 9000 Ghent (Belgium)

E-mail:Chris.Stevens@UGent.be

[b] Dr. E. I. P. Delbeke, Prof. K. M. Van Geem

LCT, Department of Materials, Textiles and Chemical Engineering

Ghent University, Technologiepark 125, 9052 Ghent (Belgium)

[c] J. Everaert, Dr. S. L. K. W. Roelants, Prof. W. Soetaert

InBio, Department of Biotechnology

Ghent University, Coupure Links 653, 9000 Ghent (Belgium)

[d] O. Lozach, Prof. M. Berchel, Prof. P.-A. Jaffrès

CEMCA, CNRS UMR 6521, IBSAM

Université de Brest, 6 avenue le Gorgeu, 29238 Brest (France)

[e] Dr. T. Le Gall, Prof. M. Berchel, Prof. T. Montier, Prof. P.-A. Jaffrès IBiSA SynNanoVect Platform, IBSAM, Faculté de médicine Morvan Université de Brest, Avenue Camille Desmoulins, 46 rue Félix Le Dantec, CS 51819, 29219 Brest Cedex 2 (France)

[f] Dr. T. Le Gall, Prof. T. Montier

INSERM UMR 1078, IBSAM, Faculté de médecine Morvan

Université de Brest

Avenue Camille Desmoulins, 46 rue Félix Le Dantec, CS 51819, 29219 Brest Cedex 2 (France)

[g] Prof. T. Montier

CHRU de Brest, Service de Génétique Moléculaire et d'Histocompatibilité 5 avenue Maréchal Foch, 29609 Brest Cedex (France) [h] Prof. T. Montier

DUMG, Faculté de Médecine et des Sciences de la Santé

22 avenue Camille Desmoulins, 29328 Brest (France)

[i] P. Rigole, Prof. T. Coenye

Laboratory of Pharmaceutical Biotechnology

Ghent University

Ottergemsesteenweg 460, 9000 Ghent (Belgium)

[j] Dr. M. Brennich

Synchrotron Crystallography Group

European Molecular Biology Laboratory

71 Avenue des Martyrs, 38042 Grenoble (France)

[k] Dr. M. Brennich

Institut Laue-Langevin

Grenoble, Beamline D16, Cedex 9, 38042, Grenoble (France)

[I] Dr. N. Baccile

UPMC Univ Paris 06, CNRS, Collège de France

Laboratoire de Chimie de la Matière Condensée de Paris

Sorbonne Université, UMR 7574, 75005, Paris (France)

[m] Dr. S. L. K. W. Roelants, Prof. W. Soetaert

Bio Base Europe Pilot Plant (BBEU)

Rodenhuizenkaai 1, 9042 Ghent (Desteldonk) (Belgium)

[n] Prof. I. N. A. Van Bogaert

Centre for Synthetic Biology, Department of Biotechnology Ghent University, Coupure Links 653, 9000 Ghent (Belgium)

$\square$ Supporting Information and the ORCID identification number(s) for the

(iD author(s) of this article can be found under:

https://doi.org/10.1002/cssc.201900721. 
When renewable resources with a complex structure can directly be used as building blocks for chemical derivatization, the number of reaction steps and the associated production cost could be drastically reduced. This approach can make optimal use of the high complexity inherent to these compounds and the high oxidation state they already possess. The two critical hurdles for developing an economical viable synthesis pathway are related to the purity and the availability of the renewable feedstock. The synthesis of bio-inspired amphiphiles is another strategy worth evaluating as it permits the efficacy of the synthesis to be increased.

In this respect, sophorolipid biosurfactants can be regarded as excellent renewable resources for chemical derivatization. ${ }^{[3]}$ They are glycolipid biosurfactants, produced by different yeast species through fermentation of renewable resources. ${ }^{[4]}$ Starmerella bombicola is the preferred production organism, for which a production of up to $400 \mathrm{~g} \mathrm{~L}^{-1}$ was reported. [4a] Sophorolipids are amphiphilic molecules, consisting of sophorose as the hydrophilic head and a fatty acid (mostly oleic acid) as the lipid tail, and can therefore lower the surface tension of water from 72.8 to $30-40 \mathrm{~m} \mathrm{~N} \mathrm{~m}^{-1}$ and display a critical micelle concentration of $40-100 \mathrm{mg} \mathrm{L}^{-1} \cdot{ }^{[4,5]}$ Their emulsifying properties can be applied for oil and hydrocarbon recovery and for soil and water decontamination. ${ }^{[6]}$ Microbial production results in the formation of different sophorolipid derivatives with diacetylated $C_{18: 1}$ sophorolipid lactone 1 and $C_{18: 1}$ sophorolipid acid 2 being the major fermentation compounds (Figure 1). Natural sophorolipids possess interesting biological activities, such as anticancer, antimicrobial, dermatological, immunoregulatory, spermicidal, and antiviral activities. ${ }^{[7]}$ In addition, they possess self-assembly properties, which results in the formation of nanostructures with supramolecular chirality. ${ }^{[8]}$ Selective production of specific sophorolipid lactone or acid derivatives can be obtained with genetically modified S. bombicola strains..$^{[9]}$ When feeding pure hydrophobic substrates to these modified strains, production of one single sophorolipid derivative can be obtained. ${ }^{[10]}$

Sophorolipids are considered as one of the most promising classes of biosurfactants, mainly owing to their production as a homogeneous product in high quantity. ${ }^{[4 a, 11]}$ In contrast to the first generation of biosurfactants, such as the alkylpolyglucosides (APGs), which are produced chemically from renewable resources, sophorolipids belong to the second-generation biosurfactants, which are produced by microorganisms through a biotechnological approach. This offers the advantage that they contain a rare hydrophilic head (sophorose) in combination with a specific chirality in the lipid tail and at the anomeric positions, both features that are not easily accessible by chemical synthesis. ${ }^{[12]}$ In our previous work, a modification pathway was developed towards a set of 18 quaternary ammonium sophorolipids, starting from the diacetylated sophorolipid lactone 1 via an intermediate sophorolipid aldehyde 3 (Scheme 1). ${ }^{[13]}$ Of all the tested derivatives, quaternary ammonium sophorolipids $\mathbf{5} \mathbf{a}$ and $\mathbf{5} \mathbf{b}$ with a long chain $\left(\mathrm{C}_{18}\right)$ on the nitrogen atom proved to be the most interesting and possessed good antimicrobial activities and were also able to transfect eukaryotic cells. ${ }^{[13-14]}$ The synthesis of the aldehyde intermediate was extended to the synthesis of a $C_{12}$ sophorolipid aldehyde derivative 8 by incorporation of petroselinic acid 6 in the sophorolipid structure through fermentation (Scheme 2) ${ }^{[15]}$ The ozonoly- sis and reductive amination can be considered as the crucial reaction steps amongst the reaction procedure depicted in Scheme 1, resulting in an overall yield of $23 \% .^{[3,16]}$ Heightening the yields of each reaction step towards $90 \%$ (e.g., by avoiding automated chromatography purification) could increase the overall yield of the reaction pathway up to $71 \%$. The carbon efficiencies (CE) for sophorolipid aldehyde $\mathbf{3}$ and quaternary ammonium sophorolipids 5 amounted, respectively, to $69 \%$ and $60 \%$. Their respective atom efficiencies (AE) were, respectively, $62 \%$ and $55 \%$. For both numbers, the valorization of the methyl 9-oxononanoate byproduct resulting from the ozonolysis step is taken into account. The use of green solvents was particularly focused on within the reaction pathway, resulting in the replacement of dichloromethane with methanol for the ozonolysis step. ${ }^{[10]}$ Besides the synthesis of the aforementioned quaternary ammonium sophorolipids, the sophorolipid modification was also extended towards sophorolipid amine oxides and bolaamphiphilic sophorolipids. ${ }^{[3,10]}$ Both classes of sophorolipids have been evaluated for their antimicrobial properties and an assessment of the transfection efficiencies was also made for the bolaamphiphilic derivatives.

In this work, the synthesis of a new set of long-chained quaternary ammonium sophorolipids is described starting from both the oleic acid-based aldehyde intermediate $\left(C_{9}\right) 3$ and the petroselinic acid-based aldehyde intermediate $\left(C_{12}\right)$ 8. Dodecyl, pentadecyl, and octadecyl groups are introduced on the nitrogen atom to evaluate the influence of the length of the nitrogen substituent, the total length of the sophorolipid tail, and the position of the nitrogen atom for derivatives with the same total chain length. The new quaternary ammonium sophorolipids are evaluated for their antimicrobial, transfection, and self-assembly properties. Similar methodologies and microbial strains were used to ensure the comparability of the results between the different classes of sophorolipid derivatives. $^{[3,10]}$

\section{Results and Discussion}

\section{Synthesis of the new derivatives}

The long-chain quaternary ammonium sophorolipids were synthesized according to the previously described pathway (Scheme 3). ${ }^{[13]}$ Oleic acid-based sophorolipid aldehyde 3 and petroselinic acid-based sophorolipid aldehyde $\mathbf{8}$ were subjected to reductive amination with $N$-methyl- $N$-dodecylamine, pentadecylamine, and $\mathrm{N}$-methyl- $\mathrm{N}$-octadecylamine, yielding the resulting sophorolipid amines 9 and $\mathbf{1 0}$. For the $\mathrm{N}$-dodecyl and $\mathrm{N}$-octadecyl sophorolipid amines $9 \mathrm{~b}, 10 \mathrm{a}$, and $10 \mathrm{c}$, the quaternization towards quaternary ammonium sophorolipids $\mathbf{4 d}$, $11 \mathrm{a}, 11 \mathrm{~b}$, and $11 \mathrm{~d}$ was performed with 5 equivalents of methyl iodide or butyl iodide in a pressure vial for $18 \mathrm{~h}$ (methyl iodide) or $48 \mathrm{~h}$ (butyl iodide) at $80^{\circ} \mathrm{C}$, as previously described. ${ }^{[13]}$ For the $\mathrm{N}$-pentadecyl sophorolipid amines $\mathbf{9 a}$ and $10 \mathrm{~b}$, the quaternization towards quaternary ammonium sophorolipids $4 \mathrm{c}$ and $11 \mathrm{c}$ was performed with 10 equivalents of methyl iodide and 2 equivalents of $\mathrm{K}_{2} \mathrm{CO}_{3}$ in a pressure vial for $18 \mathrm{~h}$ at $80^{\circ} \mathrm{C}$. In a final step, the sugar head group was deacetylated with triethylamine in a mixture of methanol and water. Evaporation of the reagent, solvent, and methyl acetate byproduct yielded the pure quaternary ammonium sophorolipids 5 and 12. For all new derivatives, the overall reaction yield, 
carbon efficiency, and atom efficiency are in the same range as for the previously synthesized quaternary ammonium sophorolipids $\mathbf{5}$ a and $\mathbf{5} \mathbf{b}$.

\section{Evaluation of the antimicrobial activity}

The antimicrobial activity of the peracetylated quaternary ammonium sophorolipids $\mathbf{4}$ and $\mathbf{1 1}$ and the deprotected quaternary ammonium sophorolipids $\mathbf{5}$ and $\mathbf{1 2}$ was evaluated against clinically relevant test organisms. These include the Gram-negative bacteria Escherichia coli LMG 8063, Klebsiella pneumoniae LMG 2095, and Pseudomonas aeruginosa PAO1, and the Grampositive bacteria Staphylococcus aureus ATCC 6538 and Staphylococcus aureus Mu50. The bioassay was carried out in 96-well plates with approximately $5 \times 10^{4}$ bacteria in a concentration series ranging from 1000 to $0.48 \mu \mathrm{g} \mathrm{mL}^{-1}$ of the test compound (final volume of $200 \mu \mathrm{L}$ ). Both the minimal inhibition concentration (MIC, that is, the lowest concentration that inhibits growth) and minimal bactericidal concentration (MBC, that is, the lowest concentration that kills all cells) values were determined for most compounds and compared with those obtained for previously synthesized quaternary ammonium sophorolipids $\mathbf{4 a}, \mathbf{4}$ b, $\mathbf{5}$ a, and $\mathbf{5} \mathbf{b}$ (see the Supporting Information, Table S1). All activities were determined in duplicate or triplicate, ensuring reproducibility when the repetitions do not differ more than one dilution. The highest value is reported when a higher difference was obtained.

Several of the derivatives showed modest activity against the Gram-negative bacteria with the highest activity obtained for the deprotected $\mathrm{N}$-dodecyl and $\mathrm{N}$-pentadecyl derivatives. Modest to high activities were obtained for all derivatives against the Gram-positive bacteria. For the acetylated quaternary ammonium salts, increasing activity is observed with a decrease in chain length, with the lowest MIC and MBC values obtained for the $\mathrm{N}, \mathrm{N}$-dimethyl- $\mathrm{N}$-dodecyl derivative $11 \mathrm{~d}$. For the deprotected quaternary ammonium sophorolipids, an opposite trend is observed, that is, an increasing activity with an increase in chain length. The lowest MIC and MBC values are obtained for the previously synthesized derivatives $\mathbf{5} \mathbf{a}$ and $\mathbf{5} \mathbf{b}$. The MIC and MBC values were converted based on their molecular weight for a better comparison of the active derivatives (Table 1). On this basis, the peracetylated $\mathrm{N}, \mathrm{N}$-dimethyl- $\mathrm{N}$-dodecyl derivative $\mathbf{1 1} \mathbf{d}$ performs slightly better than the previously synthesized derivatives $\mathbf{5}$ a and $\mathbf{5} \mathbf{b}$.

The natural sophorolipid lactones and acids were also included in the antimicrobial analysis. The activity for oleic acidbased sophorolipid lactone $\mathbf{1}$ and petroselinic acid-based sophorolipid lactone $\mathbf{7}$ are displayed in Table 1. For the oleic and petroselinic acid-based sophorolipid acids, MIC values of $>1000 \mu \mathrm{gL}^{-1}$ (>1607 $\mu \mathrm{M}$ ) were obtained against all evaluated bacteria. An increase in the antimicrobial activity by a factor 100 through chemical modification is illustrated by these results.
In our previous work, the antibiotic gentamicin sulfate was used as a reference compound and compounds $4 a, 4 b, 5 a$, and $\mathbf{5} \mathbf{b}$ proved to be more active against the $S$. aureus strain. However, the fact that gentamicin sulfate is mostly active against Gram-negative strains makes it difficult to give an appreciation of the activity of the quaternary ammonium sophorolipids in comparison with this antibiotic. In this work, a methicillin-resistant Staphylococcus aureus (MRSA) strain with vancomycin resistance (S. aureus Mu50) is included. MIC values for activity of reference antimicrobial agents such as vancomycin and clindamycin against this $S$. aureus Mu50 were reported to be $8 \mu \mathrm{g} \mathrm{mL}^{-1}(=6 \mu \mathrm{M})$ and $512 \mu \mathrm{g} \mathrm{mL}^{-1} \quad(=1205 \mu \mathrm{M})$, respectively, and the MIC value for activity of tobramycin against $P$. aeruginosa PAO1 was reported to be $2 \mu \mathrm{g} \mathrm{mL}^{-1}$ (=4 $\left.\mu \mathrm{M}\right) .^{[17]}$ Therefore, the activities obtained with the quaternary ammonium sophorolipids against both $S$. aureus strains are reasonably good. However, it should be taken into account that these results were obtained under in vitro conditions and that further in vivo testing would be necessary to determine the actual antibiotic potential of these compounds. In a next step, the potential adverse effects towards eukaryotic cells should be evaluated to know whether cytotoxicity occurs at higher concentrations than antimicrobial effects. In the evaluation of the transfection efficiency, cell viability was taken into account for these compounds formulated with 1,2-dioleyl-sn-glycero-3phosphoethanolamine (DOPE) (see below).

To evaluate the influence of the carbohydrate headgroup on the antimicrobial properties, the quaternary ammonium sophorolipids $\mathbf{5} \mathbf{a}$ and $\mathbf{5} \mathbf{b}$ were compared with the previously synthesized deglycosylated derivatives 13 and 14 (Figure 2). ${ }^{[14]}$ None of the deglycosylated derivatives showed activity against the Gram-negative bacteria and only the MIC and MBC values against the Gram-positive bacteria are presented (Table S2).

The highest activity was observed for the deprotected quaternary ammonium sophorolipids $\mathbf{5} \mathbf{a}$ and $\mathbf{5} \mathbf{b}$ against both $S$. aureus strains, especially when compared on the basis of their molecular weight (Table 2). This clearly indicates that the presence of the carbohydrate headgroup has a positive effect on the antimicrobial activity. Moreover, the hydroxylated quaternary ammonium salts $\mathbf{1 3}$ perform generally better than the non-hydroxylated quaternary ammonium salts 14 . In view of these results, it can be hypothesized that the increased hydrophilic character of the compounds results in an increased antimicrobial activity. The antimicrobial activity of compounds $13 \mathrm{a} / \mathrm{b}$ and $14 \mathrm{a} / \mathrm{b}$ is most likely due to their quaternary ammo- 
nium group, which is known for its antimicrobial activity. ${ }^{[18]}$ However, no conclusions on the mode of action can be made based on these data. Two hypotheses can be made. On the one hand, the antimicrobial properties can be attributed to a surfactant effect. The sugar headgroup increases the amphiphilic nature of the sophorolipid compounds, their micelleforming properties, their transport towards the membrane, and the fusion with the membrane. Other glycolipids, such amphotericin B, are known to be good antibiotics. ${ }^{[19]}$ To support this hypothesis, the quaternary ammonium sophorolipids should form micelles in water, which was verified in the analysis of their self-assembly properties (see below). On the other hand, the sugar headgroup itself could also play a role. A combined effect between the sugar headgroup and the micellar environment of compounds $\mathbf{5} \mathrm{a} / \mathrm{b}$ is then a possibility, although this is difficult to observe. Nonetheless, it was demonstrated that sophorolipids, covalently linked to a gold surface through their acid group, displayed surface antimicrobial properties against various Gram-positive (L. ivanovii, E. faecalis, S. epidermidis, S. puogenes) and Gram-negative (E. coli, P. aeruginosa, S. typhymurium) bacteria by membrane lysis. ${ }^{[20]}$ These effects are attributed to a direct mode of action between the sugar headgroup and the bacterial cell envelope: given the covalent binding to the gold surface, the lipid tail cannot interfere with the membrane and covalently grafted fatty acids used as controls did not show any antimicrobial effect. These findings exclude the classical surfactant effect as a mode of action for these immobilized sophorolipids as micelle formation is not possible and point towards a specific sophorose/cell envelope interaction. In the antimicrobial evaluation of the previously synthesized set of quaternary ammonium sophorolipids, it was demonstrated by microscopy analysis that cell lysis occurred at the active concentrations. However, this can also be supported by the hypothesis that disruption of the bacterial lipid membranes occurs through electrostatic and hydrophobic interactions, as reported for quaternary ammonium compounds and peptides. ${ }^{[18,21]}$

The deprotected quaternary ammonium sophorolipids $\mathbf{5 a}$ and $\mathbf{5} \mathbf{b}$ were also evaluated for their ability to affect an already established biofilm of S. aureus ATCC 6538 and S. aureus Mu50. This biofilm assay was performed in 96-well plates with previously formed biofilms after removal of the non-adhered cells. At a concentration of $20 \mu \mathrm{g} \mathrm{mL}^{-1}$ of the test compound, no effect was observed for both compounds against both $S$. aureus strains. This concentration was higher than both the MIC and MBC values of both compounds.

\section{Evaluation of the transfection efficiency}

Transfection efficiencies were evaluated in a similar way as for the previously synthesized quaternary ammonium sophorolipids $\mathbf{5} \mathbf{a}$ and $\mathbf{5} \mathbf{b}$ for which high transfection capacities have been reported. ${ }^{[14]}$ The commercial lipofection reagent Lipofectamine 3000 (LFM) was used as a reference compound in the transfection experiments. Cationic lipid amphiphiles can be used for the compaction and delivery of plasmid DNA (pDNA) and nucleic acids to different cell lines, both for in vitro and in vivo applications. ${ }^{[22]}$ Renewable based gene delivery vectors are expected to have an increased biocompatibility and are therefore of great interest. ${ }^{[23]}$

The deprotected oleic acid-based quaternary ammonium sophorolipids $\mathbf{5}$ and petroselinic acid-based quaternary ammonium sophorolipids 12 were evaluated by the lipid film hydration method for their ability to form supramolecular aggregates in an aqueous solution. The size of the particles and their surface charge were determined for all solutions by dynamic light scattering (DLS) and zeta measurements, respectively. To successfully evaluate the suitability of quaternary ammonium salts as vectors for gene delivery, formation of a homogeneous formulation is a necessary prerequisite. Formulations of the compounds were prepared with or without DOPE. Formulation with DOPE proved to be necessary to obtain more homogeneous formulations (Table 3 ). All zeta potentials were clearly positive, as expected for liposomes, or micelles, generated from cationic lipid derivatives.

For all formulations, pDNA retardation assays by agarose gel electrophoresis were used to evaluate their capacity to compact pDNA (Figure 3). This was performed at different charge ratios (CR) in a similar way as for the previously synthesized quaternary ammonium sophorolipids $\mathbf{5} \mathbf{a}$ and $\mathbf{5} \mathbf{b}$. CR is defined as the number of positive charges provided by the cationic lipid derivative divided by the number of negative charges carried by the pDNA. The previously synthesized quaternary ammonium sophorolipids $\mathbf{5} \mathbf{a}$ and $\mathbf{5} \mathbf{b}$ showed a low capacity to complex pDNA, regardless of the CR. A similar behavior was observed here for most of the new compounds.

The ability to deliver DNA into three human-derived cell lines was then evaluated for the new derivatives, including 
melanoma cells (SKMEL28) and two airway epithelial cells, that is, (i) lung carcinoma (A549) and (ii) normal bronchial (16HBE) cells. The determination of the transfection efficiency was performed by highly sensitive luminescence measurements by using a reporter (luciferase-encoding) pDNA. Each formulation was evaluated at different $C R$, ranging from 1 to 4 .

It was previously demonstrated that quaternary ammonium sophorolipids $\mathbf{5 a}$ and $\mathbf{5 b}$ efficiently transfected the 16HBE and A549 cell lines, whereas lower efficiencies were obtained for the transfection of the SKMEL28 cell line. All six new quaterna-ry ammonium sophorolipids were able to transfect the DNA in the three tested cell lines (Figure 4 and Figure S1). The best re-sults were obtained with quaternary ammonium sophorolipids $\mathbf{1 2} \mathrm{d}$, and in a lesser extent $\mathbf{5 c}$, for which higher transfection efficiencies were obtained with all cell lines than for the previ-ously evaluated compounds $\mathbf{5} \mathbf{a}$ and $\mathbf{5 b}$. Regarding the toxicity of the new derivatives, all new formulations with DOPE were weakly toxic for the A549 and SKMEL28 cell lines (Figure 5 and Figure S2). As known, LFM displays a weak toxicity at CR2 and a strong toxicity at CR4 on the A549 and 16HBE cell lines.

Derivatives $\mathbf{5 c}$ and $\mathbf{1 2} \mathbf{d}$ have the same total length (24C) but with the nitrogen atom at a different position, indicating that the total length of the sophorolipid tail has an effect on the transfection efficiencies. The highest transfection efficiency was obtained for derivative $\mathbf{1 2} \mathrm{d}$, which has two lipophilic/aliphatic fragments with the same length $\left(C_{12}\right)$.

\section{Evaluation of the self-assembly properties}

In view of correlating the antimicrobial and transfection properties of the quaternary ammonium sophorolipids, their self-assembly behavior in water was evaluated by small-angle X-ray scattering (SAXS) analysis and the results were compared with the previous set of synthesized compounds. ${ }^{[13]}$ All samples were analyzed in milli- $\mathrm{Q}$ grade water in a broad concentration range $\left(0.78-100 \mathrm{mg} \mathrm{mL}^{-1}=0.84-153 \mathrm{~mm}\right)$ without $\mathrm{pH}$ changes and within $24 \mathrm{~h}$ after sample preparation. Only the deprotected quaternary ammonium sophorolipids 5 and 12 were evaluated as the peracetylated derivatives are poorly soluble in water. Figure 6 presents a series of quaternary ammonium sophorolipid derivatives at a concentration of $3.13 \mathrm{mg} \mathrm{mL}^{-1}$

(=3.35-4.79 mM), which were reported in our previous work, comparing the effects of the different substituents on the nitrogen atom on the self-assembly properties. ${ }^{[13]}$ As SAXS is not a highly sensitive technique, this selective concentration was selected for presentation because it is the closest to the antimicrobial and transfection data with an acceptable signal-to-noise ratio. Of all tested samples and for any concentration value, only compounds $\mathbf{5} \mathbf{a}$ and $\mathbf{5} \mathbf{b}$, having octadecyl chain substituents, display a scattering response. This is characterized by a plateau at low $q$ values and by an oscillation in a $q$ range between $1 \mathrm{~nm}^{-1}$ and $3 \mathrm{~nm}^{-1}$ (Figure 6).

The scattering profile of compounds $\mathbf{5} \mathbf{a}$ and $\mathbf{5} \mathbf{b}$ is typical for spheroidal micelles, of which the radius of gyration $\left(R_{\mathrm{g}}\right)$ can be estimated by classical Guinier analysis of the SAXS data. ${ }^{[2]}$ Compounds $\mathbf{5} \mathbf{a}$ and $\mathbf{5} \mathbf{b}$ have typical $R_{\mathrm{g}}$ values on the order of $3 \mathrm{~nm}$ (Table 4). In this simplistic hypothesis of spherical micelles, the relationship between $R_{\mathrm{g}}$ and the radius of the micelle $(R)$ is given by Equation (1):
$R=\sqrt{5 / 3 R_{g}}$

thus providing a radius on the order of $4 \mathrm{~nm}$. By using the classical Tanford formula $\left(I_{c}(\AA)=1.5+1.264 n_{c}\right.$, with $I_{c}$ and $n_{c}$ being the hydrocarbon chain length and the number of the carbon atoms in the chain, respectively $)^{[25]}$ to estimate the length of a fully extended hydrocarbon chain, one calculates an overall molecular size of about $4.6 \mathrm{~nm} .{ }^{[26]}$ This is composed as follows in the sophorolipid structure: $C_{18}=2.4 \mathrm{~nm}$ and $C_{8}=$ $1.2 \mathrm{~nm}$, whereas the sophorose disaccharide is evaluated to be about $1 \mathrm{~nm}$ by comparison to other disaccharides. ${ }^{[27]}$ Given the above, one can affirm that the size of $R$, determined by the Guinier approach, is comparable with the size of compound$\mathrm{s} \mathbf{5} \mathbf{a}$ and $\mathbf{5} \mathbf{b}$. This result is in better agreement with the findings for standard amphiphiles like alkylammonium surfactants, than for bolaform acidic sophorolipids, because, in the latter case, the micellar radius is comparable to half of the size of the molecule, as predicted for bolaform surfactants. ${ }^{[28]} \mathrm{Howev}$ er, one must take the analysis above as a merely qualitative approach owing to the crude approximations assumed in the SAXS data treatment (Guinier model, spherical shape). A deeper analysis of the micellar structure for these compounds, out of the scope of this work, can be found in our recent article where both model-independent (Guinier analysis) and model-dependent (fitting by using a core-shell form factor model) are employed and compared. ${ }^{[29]}$ Finally, all compounds presented in Figure $\mathbf{6}$ other than $\mathbf{5} \mathrm{a}$ and $\mathbf{5} \mathrm{b}$ provide at equivalent concentration no significant scattering, showing poor self-assembly in water. The difference between the good self-assembly properties of compounds $\mathbf{5} \mathbf{a}$ and $\mathbf{5} \mathbf{b}$ and all other compounds can most likely be attributed to the presence of the long aliphatic chain, which is necessary to introduce van der Waals hydrophobic forces, required to drive the self-assembly of an amphiphile in water. ${ }^{[26,30]}$

Similar results have been observed for the new set of longchain quaternary ammonium sophorolipids 5 (c, d) and 12 (a, c, d), which all have a similar scattering response, typical for spheroidal micelles (Figure 7). For all compounds, the quaternary ammonium group is connected to a long aliphatic tail $\left(C_{12}, C_{15}\right.$, or $\left.C_{18}\right)$, which constitutes the driving force for their self-assembly properties in water. Guinier analysis (Table 4) of the corresponding SAXS data nicely shows that $R_{\mathrm{g}}$ increases with increasing hydrocarbon chain length connected to the ammonium group. For instance, one finds for the compounds 5 series: $R_{\mathrm{g}}(5 \mathrm{~d})=2.6 \pm 0.2 \mathrm{~nm}, R_{\mathrm{g}}(5 \mathrm{c})=2.9 \pm 0.1 \mathrm{~nm}$, and $R_{\mathrm{g}}(5 \mathrm{a})=3.1 \pm 0.1 \mathrm{~nm}$, with a corresponding increase in the secondary hydrocarbon tail comprised between $C_{12}$ for $\mathbf{5} \mathbf{d}$ and $C_{18}$ for $5 \mathrm{a}$. This trend logically reflects the upward (that is, towards higher $q$ values) shift of the scattering profiles when going from long $\left(C_{18}\right)$ to short $\left(C_{12}\right)$ alkylammonium chains in both the $\mathbf{5}(\mathrm{a}, \mathrm{c}, \mathrm{d})$ and $\mathbf{1 2}(\mathrm{a}, \mathrm{c}, \mathrm{d})$ sample series, respectively analyzed in our recent article under the sample codes $\mathbf{1}(\mathbf{f}, \mathbf{h}, \mathbf{i})$ and 1 (j, k, I). ${ }^{[29]}$

A more quantitative analysis can be found in this article, where the SAXS data of samples $\mathbf{5}(\mathbf{a}, \mathbf{c}, \mathbf{d})(\equiv \mathbf{1}(\mathbf{f}, \mathbf{h}, \mathbf{i}))$ and 12 $(\mathbf{a}, \mathbf{c}, \mathbf{d})(\equiv \mathbf{1}(\mathbf{j}, \mathbf{k}, \mathrm{I}))$ were fitted by using a core-shell sphere model form factor, where the core and shell regions, respectively, correspond to the alkylammonium and alkyl-sophorose parts of the molecules. We find that samples $\mathbf{5 a}, \mathbf{5 c}$, and $\mathbf{5 d}$ ( $\mathbf{~} \mathbf{f}, \mathbf{1} \mathbf{h}$, and $\mathbf{1} \mathbf{i}$ in Ref. [29]), respectively, have a core radius of 
1.7, 1.5, and $1.0 \mathrm{~nm}$, whereas samples $12 \mathrm{a}, \mathbf{1 2} \mathrm{c}$, and $\mathbf{1 2} \mathbf{d}(\mathbf{1} \mathbf{j}$, $1 \mathbf{k}$, and $1 \mathrm{l}$ in Ref. [29]), respectively, have a core radius of 1.6 , 1.4 , and $1.0 \mathrm{~nm}$. The shell thickness is $1.7 \pm 0.1 \mathrm{~nm}$ on average, independent of the length of the aliphatic spacer and/or chain. This analysis confirms that the increase in the overall micellar size is most likely attributed to the increasing chain length, as expected for classical alkyltrimethylammonium surfactants. ${ }^{[31]}$ The SAXS data demonstrate the remarkable self-assembly properties of compounds $\mathbf{5}(\mathbf{a}, \mathbf{b}, \mathbf{c}, \mathbf{d})$ and $\mathbf{1 2}(\mathbf{a}, \mathbf{c}, \mathbf{d})$ ), as low as $3.35-4.79 \mathrm{~mm}$, thus being consistent with the "surfactant effect" hypothesis for the antimicrobial activity (see above), which is commonly evoked to explain the membrane-disruption properties of surfactants in general. ${ }^{[32]}$ In particular, antimicrobial effects of quaternary ammonium surfactants have been known since the first half of the 20th century. ${ }^{[33]}$ If both quaternary ammonium compounds and sophorolipids are known to have antimicrobial properties, our data demonstrates that the presence of both a sophorose and a quaternary ammonium unit is not sufficient for an efficient antimicrobial effect, which only occurs when the compound has specific self-assembly properties.

As far as the relationship between self-assembly and transfection is concerned, the explanation is less straightforward. The main fact consists of the enhanced transfection properties of only those compounds that independently self-assemble into micelles. However, transfection and self-assembly are measured under different conditions. Indeed, the liposomal solutions were prepared by mixing sophorolipids with DOPE in a 1:1 molar ratio at a concentration of $1.5 \mathrm{~mm}$ of sophorolipids. DOPE also contributes to the organization of the supramolecular packing, thus leading to aggregates featuring sizes ranging from 50 to $230 \mathrm{~nm}$ (DLS measurements). On the other hand, samples from SAXS measurements were composed of sophorolipids alone and featured higher concentrations (0.78$100 \mathrm{mg} \mathrm{mL}^{-1}=0.84$ to $153 \mathrm{~mm}$ ). The results for different concentrations of the same compound were all coherent. Mixtures with DOPE were not included as SAXS can hardly discriminate between coexisting micelles and vesicles, which both give a signal in the same $q$ range and the sensitivity of the SAXS analysis is rather limited in the $0.5-1 \mathrm{mg} \mathrm{mL}^{-1}$ range. Based on these data, we can draw the following conclusions: 1) for the antimicrobial activity, the sophorolipids were dissolved alone (without DOPE) in Mueller Hinton Broth and some of them form micelles. They interact with the bacterial cell wall and induce variable bactericidal action; ${ }^{[33,34]}$ 2) when formulated with DOPE, and thanks to DOPE, it is expected that quaternary ammonium derivatives of sophorolipids with a long aliphatic chain can self-assemble with the phospholipid bilayer to form a positively charged liposome with enhanced transfection efficiency. These liposomal solutions interact with pDNA and the resulting lipoplexes can be used for transfection of eukaryotic cells without high toxicity (at $C R=2$ ). However, it is not yet clear how the sophorolipid derivative integrates the liposome bilayer.

\section{Conclusions}

Novel quaternary ammonium sophorolipids were synthesized starting from both oleic and petroselinic acid-based sophorolipids. Dodecyl, pentadecyl, and octadecyl groups were introduced on the nitrogen atom to evaluate the influence of the length of the nitrogen substituent, the total length of the sophorolipid tail, and the position of the nitrogen atom for derivatives with the same total length. The new quaternary ammonium sophorolipids were evaluated for their antimicrobial, transfection, and self-assembly properties. All new derivatives were active against the Gram-positive bacteria Staphylococcus aureus ATCC 6538 and Staphylococcus aureus Mu50. The deprotected derivatives with an $\mathrm{N}$-dodecyl or $\mathrm{N}$-pentadecyl substituent also showed considerable activity against the Gram-negative bacteria Escherichia coli LMG 8063, Klebsiella pneumoniae LMG 2095, and Pseudomonas aeruginosa PAO1. It is noteworthy that some of these bacteria are part of the priority pathogens list for R\&D of new antibiotics. ${ }^{[35]}$ For the acetylated quaternary ammonium salts, increasing activity is observed with a decrease in chain length, with the highest activity obtained for the peracetylated $\mathrm{N}, \mathrm{N}$-dimethyl- $\mathrm{N}$-dodecyl derivative $\mathbf{1 1} \mathrm{d}$. For the deprotected quaternary ammonium sophorolipids, an opposite trend is observed, that is, increasing activity with an increase in chain length, with the highest activity obtained for the previously synthesized derivatives $\mathbf{5} \mathbf{a}$ and $\mathbf{5} \mathbf{b}$. On the basis of molecular weight, the peracetylated $\mathrm{N}, \mathrm{N}$-dimethyl- $\mathrm{N}$-dodecyl derivative $\mathbf{1 1} \mathbf{d}$ performs slightly better than the previously synthesized derivatives $\mathbf{5} \mathbf{a}$ and $\mathbf{5} \mathbf{b}$. Higher antimicrobial activities were obtained for the quaternary ammonium sophorolipids 5 a and $\mathbf{5} \mathrm{b}$ than for the deglycosylated derivatives 13 and 14 , indicating that increased hydrophilic character of the compounds results in an increased antimicrobial activity. Evaluation of the transfection efficiency indicated that formulation with DOPE was required for all six new derivatives to obtain homogeneous liposomal solutions and a low DNA compaction ability was observed for most compounds. All six new quaternary ammonium sophorolipids were able to transfect the DNA in the three tested cell lines (A549, 16HBE, and SKMEL28). The best results were obtained with quaternary ammonium sophorolipids $\mathbf{1 2} \mathrm{d}$, and in a lesser extent $\mathbf{5 c}$, for which higher transfection efficiencies were obtained with the three cell lines than for the previously evaluated compounds $\mathbf{5} \mathbf{a}$ and $\mathbf{5} \mathbf{b}$, and for which a low cell toxicity was also observed. These results indicate that the total length of the lipid tail and the presence of two lipid fragments with the same length have an influence on the transfection efficiency. Evaluation of the self-assembly properties indicated that the presence of a long chain on the nitrogen atom was necessary for the compounds to self-assemble in water and provide the formation of micelles. A strong correlation was found between the property of selfassembly and the antimicrobial activity and transfection efficiency. These results are promising for medical applications in which transfection efficiencies or micelle formation need to be combined with good antimicrobial properties. To further explore the application possibilities, the simultaneous antimicrobial action and transfection efficiency could be assessed by 
evaluating the transfection of eukaryotic cells in the presence of prokaryotic cells. ${ }^{[36]}$

\section{Experimental Section}

\section{Synthetic procedures}

Sophorolipid amines 9 and 10: In a $50 \mathrm{~mL}$ flask, peracetylated sophorolipid aldehyde $\mathbf{3}$ or $\mathbf{8}$ ( $2.02 \mathrm{mmol}, 1$ equiv) was dissolved in methanol $(25 \mathrm{~mL})$ and the amine $\left(2.02 \mathrm{mmol}, 1\right.$ equiv), $\mathrm{NaBH}_{3} \mathrm{CN}$ $(0.25 \mathrm{~g}, 4.04 \mathrm{mmol}, 2$ equiv), and acetic acid $(0.58 \mathrm{~mL}, 10.09 \mathrm{mmol}$, 5 equiv) were added sequentially. For reaction with pentadecylamine, the sophorolipid aldehyde and amine were stirred for $1 \mathrm{~h}$ at room temperature $\left(18^{\circ} \mathrm{C}\right)$ prior to the addition of $\mathrm{NaBH}_{3} \mathrm{CN}$ and $\mathrm{AcOH}$ to avoid a second reductive amination. The reaction mixture was stirred overnight at room temperature, concentrated under reduced pressure, and dissolved in ethyl acetate. The mixture was washed three times with a saturated $\mathrm{NaHCO}_{3}$ solution and the organic phase was dried over $\mathrm{MgSO}_{4}$, filtered, and concentrated under reduced pressure. The peracetylated sophorolipid amines were purified by automated column chromatography as a viscous colorless oil with $n$-hexane/mixture $A$ as eluent (mixture $A=16 \%$ triethylamine in ethyl acetate).

Peracetylated quaternary ammonium sophorolipids 4 and 11: In a $10 \mathrm{~mL}$ flame-dried pressure-resistant vial, peracetylated sophorolipid amine $\mathbf{9}$ or $\mathbf{1 0}$ was dissolved in dry acetonitrile. The solution was cooled to $0^{\circ} \mathrm{C}$ and the alkyl iodide (5 equiv) was added. For the $N$-pentadecyl sophorolipid amines $9 \mathrm{a}$ and $10 \mathrm{~b}$, the quaternization was performed with 10 equivalents methyl iodide and 2 equivalents $\mathrm{K}_{2} \mathrm{CO}_{3}$. The vial was closed and heated to $80^{\circ} \mathrm{C}$ for $18 \mathrm{~h}$ (methyl iodide) or $48 \mathrm{~h}$ (butyl iodide). The reaction mixture was concentrated under reduced pressure and recrystallized from diethyl ether, if necessary, to yield the peracetylated sophorolipid quaternary ammonium salt. For the $\mathrm{N}$-pentadecyl quaternary ammonium sophorolipids $\mathbf{4 c}$ and $\mathbf{1 1} \mathrm{c}$, the derivatives were dissolved in EtOAc and washed with water to remove the residual $\mathrm{K}_{2} \mathrm{CO}_{3}$.

Deprotected quaternary ammonium sophorolipids 5 and 12: In a $25 \mathrm{~mL}$ flame-dried round-bottomed flask, the peracetylated sophorolipid quaternary ammonium salt 4 or $11(0.45 \mathrm{mmol}, 1$ equiv) was dissolved in a methanol/water mixture $(1: 1)$ and $\mathrm{Et}_{3} \mathrm{~N}(13 \mathrm{~mL}$, $0.90 \mathrm{mmol}, 2$ equiv) was added. The mixture was stirred for $2 \mathrm{~h}$ at reflux temperature and concentrated under reduced pressure to yield pure deprotected quaternary ammonium sophorolipid $\mathbf{5}$ or 12.

\section{Materials and methods}

General instrumental methods: Commercially available products were used without further purification. NMR spectra were recorded at $400 \mathrm{MHz}\left({ }^{1} \mathrm{H}\right)$ and $100 \mathrm{MHz}\left({ }^{13} \mathrm{C}\right)$ in $\mathrm{CDCl}_{3}$ or $\mathrm{MeOD}$ with a Bruker Avance III Nanobay $400 \mathrm{MHz}$ spectrometer at room temperature. Low-resolution mass spectra were recorded with a single quadrupole mass spectrometer (ESI, $70 \mathrm{eV}$ ). High-resolution mass spectra were obtained with a time-of-flight (TOF) mass spectrometer (ESI or APCI). Melting points were determined with a Wagner and Munz Kofler-Heizbank (Type WME) instrument.

Determination of the antimicrobial activity: Antimicrobial activity of all quaternary ammonium sophorolipids against E. coli LMG 8063, K. pneumoniae LMG 2095, P. aeruginosa PAO1, S. aureus ATCC 6538 , and S. aureus Mu50 was assessed by a broth microdilution method (CLSI, 2012). ${ }^{[37]}$ Strains with LMG designation were ob- tained from the BCCM/LMG Bacteria Collection (Ghent, Belgium), whereas strain ATCC 6538 was obtained from the American Type Culture Collection (Manassas, VA). S. aureus strain Mu50 was a kind gift from P. Vandamme (Ghent, Belgium). All strains were grown aerobically at $37^{\circ} \mathrm{C}$ on Mueller Hinton agar (LabM, Heywood, UK). The minimal inhibitory concentration (MIC) that inhibited growth completely compared with the untreated control and the minimal bactericidal concentration (MBC) at which no more surviving organisms can be recovered were used as measures of activity. MIC and MBC values were determined by using flat-bottomed 96 -well microtiter plates (TPP, Trasadingen, Switzerland). Concentrations of compounds tested ranged from 0.48 to $1000 \mu \mathrm{g} \mathrm{mL}^{-1}$ in Mueller Hinton Broth (LabM). The inoculum was standardized at approximately $5 \times 10^{4}$ colony forming units (CFU) $\mathrm{mL}^{-1}$. The plates were incubated at $37^{\circ} \mathrm{C}$ for $24 \mathrm{~h}$, and the optical density was determined at $590 \mathrm{~nm}$ by using a multilabel microtiter plate reader (Envision Xcite, PerkinElmer LAS, Waltham, MA).

For the biofilm assay, S. aureus ATCC 6538 and S. aureus Mu50 were cultured on Trypton Soy agar plates (TSA, LabM, Lancashire, UK). From these pure cultures, overnight suspensions were made by inoculating $10 \mathrm{~mL}$ Trypton Soy broth (TSB, LabM, Lancashire, UK) with a loopful of microorganisms. Both strains were grown aerobically at $37^{\circ} \mathrm{C}$. Biofilms were formed as previously described. ${ }^{[38]}$ Overnight suspensions were adjusted with TSB to an optical density of 0.05 . These optical densities correspond to approximately $2.5 \times 10^{7} \mathrm{CFU} \mathrm{mL}^{-1}$. An aliquot $(100 \mu \mathrm{L})$ of the diluted cell suspension was transferred to the wells of a polystyrene round-bottomed 96-well microtiter plate (MTP, SPL, Lifescience, Korea) and incubated at $37^{\circ} \mathrm{C}$. Blanco control wells were filled with sterile medium. The medium was removed after $4 \mathrm{~h}$ and the biofilms were rinsed with Physiological Saline (PS) to remove non-adhered cells. Fresh medium was subsequently added to the wells and the plates were further incubated for $20 \mathrm{~h}$. These biofilms were rinsed with PS and treated with $100 \mu \mathrm{L}$ of test compound at a concentration of $20 \mu \mathrm{gLL}^{-1}$ for $24 \mathrm{~h}$ at $37^{\circ} \mathrm{C}$. The treatments were removed and the biofilms were rinsed with PS. To determine the CFU, $100 \mu \mathrm{L}$ PS was added to the wells containing the treated biofilms and the MTP was sonicated and vortexed twice. The detached cells were quantified by conventional plating.

Liposome formulation: The liposomal solutions were prepared by the lipid film hydration method. A $1.5 \mathrm{~mm}$ solution (in $1 \mathrm{~mL}$ ) of each compound was prepared in chloroform, formulated with or without DOPE (1:1 compound/DOPE) and evaporated under reduced pressure to produce a thin lipid film. Water $(1 \mathrm{~mL})$ was added to rehydrate this lipid film over a time period of 7 days at room temperature. The solution was vortexed $(10 \mathrm{~s})$ and sonicated (30 min at $50^{\circ} \mathrm{C}$ ) at $45 \mathrm{kHz}$ by using a VWR ultrasonic bath. The size and zeta potential were determined for each liposomal formulation.

DNA complexation: Lipoplexes were prepared by mixing pDNA (pEGFP-Luc, Clontech) with each liposomal solution in OptiMEM (Gibco). Addition of pDNA to the liposomal solutions was performed at concentrations corresponding to $C R$ ranging from 1 to 4. The obtained mixtures were incubated at room temperature for $1 \mathrm{~h}$ before being subjected to electrophoresis in a $0.8 \%$ agarose gel at $100 \mathrm{~V}, 90 \mathrm{~mA}$. The gel was stained with SYBRgold nucleic acid gel staining (Life Technologies) and visualized under UV light by using a UV trans-illuminator (Fischer Bioblock).

Transfection efficiency: The in vitro reporter gene assay by luciferase measurement was carried out as reported previously. ${ }^{[23 b, 39]}$ Data were expressed as relative light units (RLU) per milligram of total 
proteins (means \pm SD with $n=3$ ). Lipofectamine 3000 (Invitrogene) was used as the standard.

Cell viability: The Vialight kit (Lonza) was used to estimate the viability of the cells following transfection. For this purpose, $48 \mathrm{~h}$ after exposition to the lipoplexes to evaluate, cells were lysed and their ATP content was determined, as recommended by the manufacturer. Non-transfected cells were used to express viability results in the form of percentages (\% of the reference).

Small-angle X-ray scattering (SAXS): SAXS experiments were performed at $25^{\circ} \mathrm{C}$ immediately after sample preparation with the BioSAXS BM29 beamline at the ESRF synchrotron facility (Grenoble, France) using $12.5 \mathrm{keV}$ energy and a sample-to-detector distance of $2.867 \mathrm{~m}$, imposed by the beamline standard configuration. The energy was calibrated by measuring the $L_{1}$ and $L_{\|||}$edges of platinum and the sample-to-detector distance was determined by using silver behenate $\left(d_{\text {ref }}=58.38 \AA\right) \cdot{ }^{[40]}$ For this experiment, the automatic sample changer for liquids was employed using the 96well plates and about $100 \mu \mathrm{L}$ of each sample. ${ }^{[41]}$ The liquid sample is automatically loaded into a $1.8 \mathrm{~mm}$ quartz glass capillary and ten acquisitions of $1 \mathrm{~s}$ each are taken as the sample passes the beam. Individual frames are manually controlled for systematic changes and averaged for better statistics if none are found. Eventual changes can be either due to intrinsic sample heterogeneity or radiation damage. The signal of the Pilatus 1M 2D detector, used to record the data, is integrated azimuthally with PyFAl to obtain the $I(q)$ vs. $q$ spectrum $\left(q=\frac{4 \pi}{\lambda} \sin \theta\right.$, where $2 \theta$ is the scattering angle) after masking systematically wrong pixels and the beam stop shadow. ${ }^{[42]}$ Absolute intensity units were determined by measuring the scattering signal of water $\left(0.0163 \mathrm{~cm}^{-1}\right)$. Radii of gyration, $R_{\mathrm{g}}$, have been calculated by Guinier analysis of the SAXS data by using SasView software, available free of charge at the developer's website (http://www.sasview.org).

\section{Acknowledgements}

The research leading to these results has received funding from the Long-Term Structural Methusalem funding by the Flemish Government (grant number BOF09/01M00409). This work received financial support from the European Synchrotron Radiation Facility (ESRF), Grenoble, France, under the experiment number MX1821. This work benefited from the use of the SasView application, originally developed under NSF award DMR0520547. SasView contains code developed with funding from the European Union's Horizon 2020 research and innovation programme under the SINE2020 project, grant agreement No 654000 .

\section{Conflict of interest}

The authors declare no conflict of interest.

Keywords: amphiphiles - biological activity - drug delivery renewable resources $\cdot$ self-assembly

[1] a) R. C. Brown, Biorenewable Resources. Engineering New Products from Agriculture, Blackwell, Hoboken, 2003, p. 286; b) J. O. Metzger, M. Eissen, C. R. Chim. 2004, 7, 569-581; c) A. A. Koutinas, C. Du, R. H. Wang, C. Webb in Production of Chemicals from Biomass (Eds.: J. H. Clark, F. E. I. Deswarte), Wiley, Chichester, 2008, pp. 77-101; d) V. Van- dermeulen, M. Van der Steen, C. V. Stevens, G. Van Huylenbroeck, Biofuels Bioprod. Biorefin. 2012, 6, 453-466.

[2] M. Chambers, M. Muecke, J. Green Building 2010, 5, 91 - 107.

[3] E. I. P. Delbeke, J. Everaert, O. Lozach, T. Le Gall, M. Berchel, T. Montier, P. A. Jaffres, P. Rigole, T. Coenye, M. Brennich, N. Baccile, S. L. K. W. Roelants, W. Soetaert, I. N. A. van Bogaert, K. M. Van Geem, C. V. Stevens, ACS Sustainable Chem. Eng. 2018, 6, 8992-9005.

[4] a) I. N. A. Van Bogaert, K. Saerens, C. De Muynck, D. Develter, W. Soetaert, E. J. Vandamme, Appl. Microbiol. Biotechnol. 2007, 76, 23-34; b) I. N. A. Van Bogaert, J. X. Zhang, W. Soetaert, Process Biochem. 2011, $46,821-833$.

[5] a) A. M. Davila, R. Marchal, J. P. Vandecasteele, J. Ind. Microbiol. 1994, 13, 249-257; b) G. Pekin, F. Vardar-Sukan, N. Kosaric, Eng. Life Sci. 2005, 5 , $357-362$.

[6] a) M. Baviere, D. Degouy, J. Lecourtier (Institut Français du Petrole, Rueil Malmaison, France), US5326407A, 1993; b) L. Pesce (Idrabel Italia S.R.L., Arenzano, Italy; Jeneil Biosurfactant Co., Saukeville, WI), WO2002062495, 2001; c) J. Ducreux, D. Ballerini, M. Baviere, C. Bocard, N. Monin (Institut Français du Pétrole, Rueil Malmaison, France), US5654192A, 1995; d) C. N. Mulligan, R. N. Yong, B. F. Gibbs, J. Hazard. Mater. 2001, 85, 111-125; e) C. N. Mulligan, R. N. Yong, B. F. Gibbs, Eng. Geol. 2001, 60, 371-380; f) C. Schippers, K. Gessner, T. Muller, T. Scheper, J. Biotechnol. 2000, 83, 189-198.

[7] a) V. K. Morya, C. Ahn, S. Jeon, E. K. Kim, Mini-Rev. Med. Chem. 2013, 13, $1761-1768$; b) E. I. P. Delbeke, M. Movsisyan, K. M. Van Geem, C. V. Stevens, Green Chem. 2016, 18, 76-104.

[8] a) N. Baccile, N. Nassif, L. Malfatti, I. N. A. Van Bogaert, W. Soetaert, G. Pehau-Arnaudet, F. Babonneau, Green Chem. 2010, 12, 1564-1567; b) N. Baccile, F. Babonneau, J. Jestin, G. Pehau-Arnaudet, I. Van Bogaert, ACS Nano 2012, 6, 4763-4776.

[9] S. L. K. W. Roelants, K. Ciesielska, S. L. De Maeseneire, B. Everaert, Q. Denon, H. Moens, B. Vanlerberghe, I. N. A. Van Bogaert, P. Van der Meeren, B. De Vreese, W. Soetaert, Biotechnol. Bioeng. 2016, 113, 550-559.

[10] E. I. P. Delbeke, S. L. K. W. Roelants, N. Matthijs, B. Everaert, W. Soetaert, T. Coenye, K. M. Van Geem, C. V. Stevens, Ind. Eng. Chem. Res. 2016, 55, $7273-7281$.

[11] M. Kjellin, I. Johansson in Surfactants from Renewable Resources (Ed.: C. V. Stevens), Wiley, Chichester, 2010, p. 320.

[12] A. Fürstner, K. Radkowski, J. Grabowski, C. Wirtz, R. Mynott, J. Org. Chem. 2000, 65, 8758-8762.

[13] E. I. P. Delbeke, B. I. Roman, G. B. Marin, K. M. Van Geem, C. V. Stevens, Green Chem. 2015, 17, 3373-3377.

[14] E. I. P. Delbeke, O. Lozach, T. Le Gall, M. Berchel, T. Montier, P. A. Jaffres, K. M. Van Geem, C. V. Stevens, Org. Biomol. Chem. 2016, 14, 3744-3751.

[15] E. I. P. Delbeke, J. Everaert, E. Uitterhaegen, S. Verweire, A. Verlee, T. Talou, W. Soetaert, I. N. A. Van Bogaert, C. V. Stevens, AMB Express 2016, 6, 28.

[16] E. Delbeke, Innovative sophorolipid analogues with tailor-made physicochemical and biological properties, Ph.D. thesis, Ghent University, Ghent, 2016, p. 194.

[17] G. Brackman, P. Cos, L. Maes, H. J. Nelis, T. Coenye, Antimicrob. Agents Chemother. 2011, 55, 2655-2661.

[18] a) C. J. Ioannou, G. W. Hanlon, S. P. Denyer, Antimicrob. Agents Chemother. 2007, 51, 296-306; b) K. Hegstad, S. Langsrud, B. T. Lunestad, A. A. Scheie, M. Sunde, S. P. Yazdankhah, Microb. Drug Resist. 2010, 16, 91 104.

[19] a) A. D. Cortés-Sánchez, H. Hernández-Sánchez, M. E. Jaramillo-Flores, Microbiol. Res. 2013, 168, 22-32; b) J. Brajtburg, W. G. Powderly, G. S. Kobayashi, G. Medoff, Antimicrob. Agents Chemother. 1990, 34, $183-$ 188.

[20] a) C. Valotteau, C. Calers, S. Casale, J. Berton, C. V. Stevens, F. Babonneau, C. M. Pradier, V. Humblot, N. Baccile, ACS Appl. Mater. Interfaces 2015, 7, 18086-18095; b) C. Valotteau, I. M. Banat, C. A. Mitchell, H. Lydon, R. Marchant, F. Babonneau, C. M. Pradier, N. Baccile, V. Humblot, Colloids Surf. B 2017, 157, 325-334.

[21] a) K. A. Brogden, Nat. Rev. Microbiol. 2005, 3, 238-250; b) F. Siedenbiedel, J. C. Tiller, Polymers 2012, 4, 46-71.

[22] a) F. Perche, T. Benvegnu, M. Berchel, L. Lebegue, C. Pichon, P. A. Jaffres, P. Midoux, Nanomedicine 2011, 7, 445-453; b) A. K. K. Leung, Y. Y. C. Tam, P. R. Cullis, Adv. Genet. 2014, 88, 71-110; c) X. Guo, L. Huang, Acc. Chem. Res. 2012, 45, 971-979; d) M. Berchel, T. Le Gall, H. Couthon- 
Gourves, J. P. Haelters, T. Montier, P. Midoux, P. Lehn, P. A. Jaffres, Biochimie 2012, 94, 33-41; e) T. Montier, T. Benvegnu, P. A. Jaffres, J. J. Yaouanc, P. Lehn, Curr. Gene Ther. 2008, 8, 296-312.

[23] a) D. L. Liu, W. H. Qiao, Z. S. Li, Y. X. Chen, X. Y. Cui, K. Li, L. H. Yu, K. L. Yan, L. M. Zhu, Y. L. Guo, L. B. Cheng, Chem. Biol. Drug Des. 2008, 71 $336-344$; b) S. S. Le Corre, M. Berchel, T. Le Gall, J. P. Haelters, P. Lehn, T. Montier, P. A. Jaffres, Eur. J. Org. Chem. 2014, $8041-8048$; c) T. Le Gall, D. Loizeau, E. Picquet, N. Carmoy, J. J. Yaouanc, L. Burel-Deschamps, P. Delepine, P. Giamarchi, P. A. Jaffres, P. Lehn, T. Montier, J. Med. Chem. 2010, 53, 1496-1508; d) M. F. Lindberg, N. Carmoy, T. Le Gall, A. Fraix, M. Berchel, C. Lorilleux, H. Couthon-Gourves, P. Bellaud, A. Fautrel, P. A. Jaffres, P. Lehn, T. Montier, Biomaterials 2012, 33, 6240-6253.

[24] O. Glatter, O. Kratky, Small-Angle X-ray Scattering, Academic Press, New York, 1982.

[25] C. Tanford, The Hydrophobic effect: Formation of Micelles and Biological Membranes, Wiley-Interscience, New York, 1973, p. 200.

[26] C. Tanford, The Hydrophobic Effect: Formation of Micelles and Biological Membranes, Wiley-Interscience, New York, 1980.

[27] a) L. R. Winther, J. Qvist, B. Halle, J. Phys. Chem. B 2012, 116, 9196-9207; b) S. Abel, F. Y. Dupradeau, E. P. Raman, A. D. MacKerell, M. Marchi, J. Phys. Chem. B 2011, 115, 487-499.

[28] a) S. Manet, A. S. Cuvier, C. Valotteau, G. C. Fadda, J. Perez, E. Karakas, S. Abel, N. Baccile, J. Phys. Chem. B 2015, 119, 13113-13133; b) R. Nagarajan, Chem. Eng. Commun. 1987, 55, 251-273.

[29] N. Baccile, E. I. P. Delbeke, M. Brennich, C. Seyrig, J. Everaert, S. L. K. W. Roelants, W. Soetaert, I. N. A. Van Bogaert, K. M. Van Geem, C. V. Stevens, J. Phys. Chem. B 2019, 123, 3841-3858.

[30] a) J. N. Israelachvili, D. J. Mitchell, B. W. Ninham, Biochim. Biophys. Acta 1977, 470, 185-201; b) J. N. Israelachvili, D. J. Mitchell, B. W. Ninham, J. Chem. Soc. Faraday Trans. 2 1976, 72, 1525-1568.

[31] R. Zana, J. Colloid Interface Sci. 1980, 78, 330-337.

[32] a) S. K. Patra, A. Alonso, F. M. Goni, Biochim. Biophys. Acta Biomembr 1998, 1373, 112-118; b) J. G. Hurdle, A. J. O'Neill, I. Chopra, R. E. Lee Nat. Rev. Microbiol. 2011, 9, 62-75.

[33] J. C. L. Resuggan, Proc. Soc. Appl. Bacteriol. 1952, 15, 166-171.

[34] a) G. M. Zeng, H. Y. Fu, H. Zhong, X. Z. Yuan, M. X. Fu, W. Wang, G. H. Huang, Biodegradation 2007, 18, 303-310; b) Y. Shabtai, D. L. Gutnick, Appl. Environ. Microbiol. 1985, 49, $192-197$; c) B. Isomaa, J. Reuter, B. M. Djupsund, Arch. Toxicol. 1976, 35, $91-96$; d) T. L. Hwang, C. Y. Hsu, I. A. Aljuffali, C. H. Chen, Y. T. Chang, J. Y. Fang, Colloids Surf. B 2015, 128, $119-126$.

[35] WHO list of bacteria for which new antibiotics are urgently needed, World Health Organization, 2017, https://www.who.int/en/news-room/detail/ 27-02-2017-who-publishes-list-of-bacteria-for-which-new-antibiotics-areurgently-needed.

[36] T. Le Gall, M. Berchel, S. Le Hir, A. Fraix, J. Y. Salaun, C. Ferec, P. Lehn, P. A. Jaffres, T. Montier, Adv. Healthcare Mater. 2013, 2, 1513-1524.

[37] Performance Standards for Antimicrobial Susceptibility Testing, TwentySecond Informational Supplement M100-S22, Vol. 32, No. 3, Clinical and Laboratory Standards Institute, Wayne, PA, USA, 2012.

[38] F. Van den Driessche, P. Rigole, G. Brackman, T. Coenye, J. Microbiol. Methods 2014, 98, 31-34.

[39] A. Fraix, T. Le Gall, M. Berchel, C. Denis, P. Lehn, T. Montier, P. A. Jaffres, Org. Biomol. Chem. 2013, 11, 1650-1658.

[40] a) http://www.esrf.eu/home/UsersAndScience/Experiments/MX/About our_beamlines/bm29.html; b) P. Pernot, A. Round, R. Barrett, A. D. Antolinos, A. Gobbo, E. Gordon, J. Huet, J. Kieffer, M. Lentini, M. Mattenet, C. Morawe, C. Mueller-Dieckmann, S. Ohlsson, W. Schmid, J. Surr, P. Theveneau, L. Zerrad, S. McSweeney, J. Synchrotron Radiat. 2013, 20, 660 664.

[41] A. Round, F. Felisaz, L. Fodinger, A. Gobbo, J. Huet, C. Villard, C. E. Blanchet, P. Pernot, S. McSweeney, M. Roessle, D. I. Svergun, F. Cipriani, Acto Crystallogr. Sect. D 2015, 71, 67-75.

[42] G. Ashiotis, A. Deschildre, Z. Nawaz, J. P. Wright, D. Karkoulis, F. E. Picca, J. Kieffer, J. Appl. Crystallogr. 2015, 48, 510-519.

Manuscript received: March 13, 2019

Revised manuscript received: May 9, 2019

Accepted manuscript online: May 13, 2019

Version of record online: July 1, 2019 

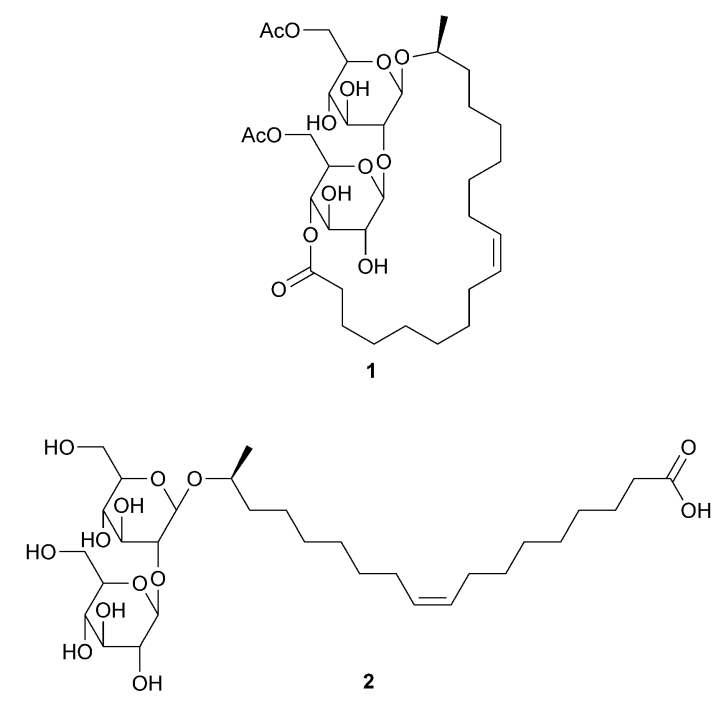

Figure 1. Diacetylated sophorolipid lactone 1 and sophorolipid acid 2.
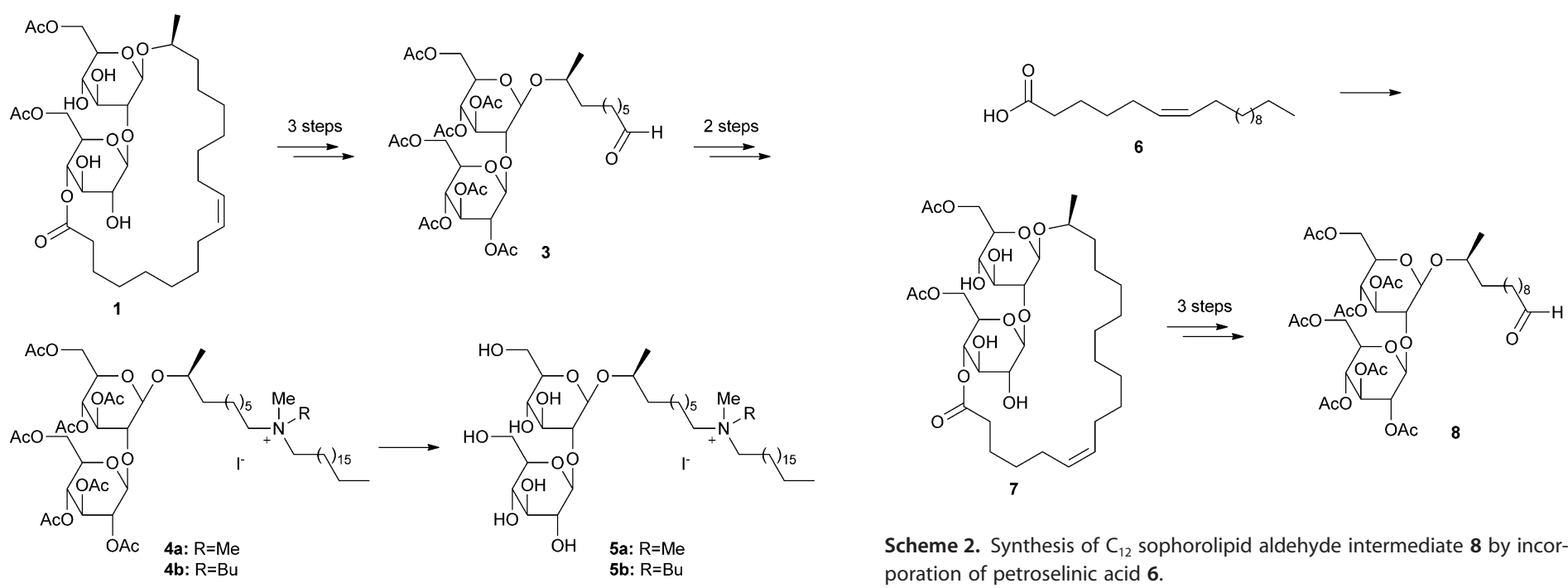

Scheme 2. Synthesis of $C_{12}$ sophorolipid aldehyde intermediate 8 by incorporation of petroselinic acid 6 .

Scheme 1. Modification pathway towards quaternary ammonium sophorolipids $\mathbf{4}$ and $\mathbf{5}$.

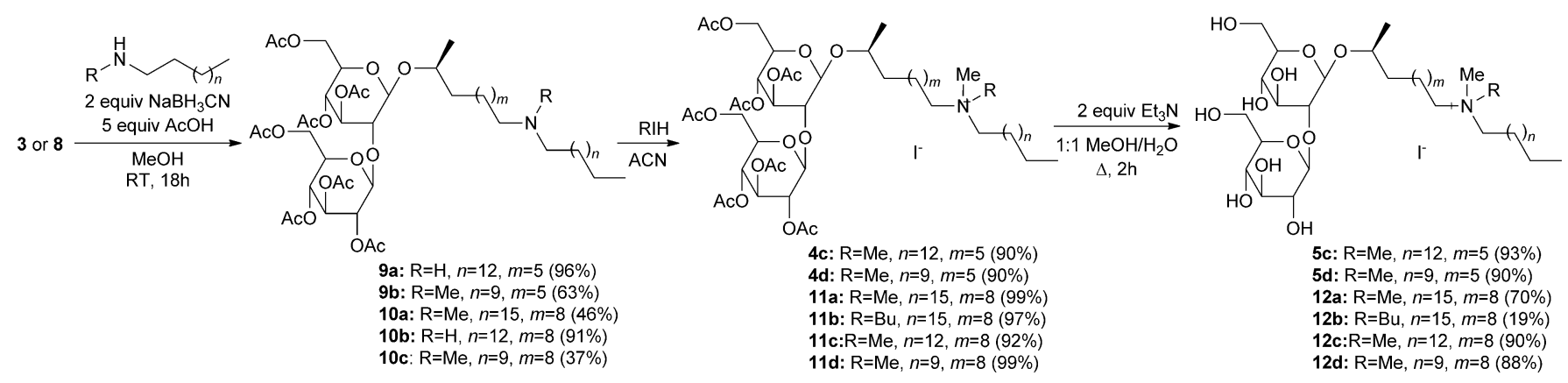

Scheme 3. Synthesis of oleic acid-based quaternary ammonium sophorolipids $\mathbf{4}$ and $\mathbf{5}$, and petroselinic acid-based quaternary ammonium sophorolipids $\mathbf{1 1}$ and 12. 


\begin{tabular}{|c|c|c|c|c|c|c|c|c|c|c|}
\hline Bacterial strain & Parameter & 1 & $4 a$ & $4 b$ & $4 c$ & $4 d$ & $5 a$ & $5 b$ & $5 c$ & $5 d$ \\
\hline \multicolumn{11}{|l|}{ OA-based derivatives } \\
\hline E. coli LMG 8063 & MIC & $>1453$ & $>843$ & $>815$ & 874 & 454 & $>1122$ & $>1071$ & 147 & 310 \\
\hline \multirow[t]{2}{*}{ K. pneumoniae LMG 2095} & MIC & $>1453$ & $>843$ & $>815$ & 874 & 113 & $>1122$ & $>1071$ & 73.6 & 310 \\
\hline & $\mathrm{MBC}$ & ND & ND & ND & ND & ND & ND & ND & 73.6 & ND \\
\hline \multirow[t]{2}{*}{ P. aeruginosa PAO1 } & MIC & $>1453$ & $>843$ & $>815$ & $>874$ & $>908$ & $>1122$ & $536^{[b]}$ & 147 & 619 \\
\hline & $\mathrm{MBC}$ & ND & ND & ND & ND & ND & ND & ND & ND & ND \\
\hline \multirow[t]{2}{*}{ S. aureus ATCC 6538} & MIC & 182 & 6.59 & 6.36 & 1.71 & 1.77 & 2.18 & 2.09 & 18.4 & 38.7 \\
\hline & $\mathrm{MBC}$ & 363 & 6.59 & 204 & 3.42 & 7.09 & 8.76 & 2.09 & 36.8 & 77.4 \\
\hline \multirow[t]{2}{*}{ S. aureus Mu50 } & MIC & 363 & 26.4 & 50.9 & 1.71 & 1.77 & 4.37 & 4.18 & 36.8 & 155 \\
\hline & $\mathrm{MBC}$ & 1453 & 52.7 & 204 & 1.71 & 3.55 & 17.5 & 16.73 & 73.6 & 310 \\
\hline \multicolumn{11}{|l|}{ PA-based derivatives } \\
\hline & & 7 & $11 \mathrm{a}$ & $11 \mathrm{~b}$ & $11 \mathrm{c}$ & $11 \mathrm{~d}$ & $12 \mathrm{a}$ & $12 b$ & $12 \mathrm{c}$ & $12 d$ \\
\hline \multirow[t]{2}{*}{ E. coli LMG 8063} & MIC & $>1453$ & $>815$ & $>788$ & 843 & 874 & $>1071$ & $>1025$ & 70.1 & 36.8 \\
\hline & $\mathrm{MBC}$ & ND & ND & ND & ND & ND & ND & ND & 140 & 73.6 \\
\hline \multirow[t]{2}{*}{ K. pneumoniae LMG 2095} & MIC & $>1453$ & $>815$ & $>788$ & 843 & 874 & 1071 & $>1025$ & 35.1 & 36.8 \\
\hline & $\mathrm{MBC}$ & ND & ND & ND & ND & ND & ND & ND & 140 & 147 \\
\hline \multirow[t]{2}{*}{ P. aeruginosa $\mathrm{PAO} 1$} & MIC & $>1453$ & $>815$ & $>788$ & $>843$ & $>874$ & 1071 & $>1025$ & 280 & 147 \\
\hline & $\mathrm{MBC}$ & ND & ND & ND & ND & ND & ND & ND & ND & ND \\
\hline \multirow[t]{2}{*}{ S. aureus ATCC 6538} & MIC & 182 & 50.9 & 98.5 & 6.59 & 1.71 & 8.37 & 16.0 & 8.76 & 18.4 \\
\hline & $\mathrm{MBC}$ & 363 & 50.9 & 394 & 13.2 & 1.71 & 8.37 & 16.0 & 17.5 & 18.4 \\
\hline \multirow[t]{2}{*}{ S. aureus Mu50 } & MIC & 363 & 407 & 394 & 6.59 & 1.71 & 16.7 & 16.0 & 8.76 & 18.4 \\
\hline & $\mathrm{MBC}$ & 1453 & 815 & $>788$ & 6.59 & 1.71 & 16.7 & 32.0 & 35.1 & 36.8 \\
\hline
\end{tabular}

\begin{tabular}{|c|c|c|c|c|c|c|c|}
\hline \multirow[t]{2}{*}{ Bacterial strain } & \multirow[t]{2}{*}{ Parameter } & \multicolumn{6}{|c|}{ MIC or MBC value ${ }^{[a]}[\mu \mathrm{mol}]$} \\
\hline & & $5 a$ & $5 \mathrm{~b}$ & $13 a$ & $13 \mathrm{~b}$ & $14 a$ & $14 b$ \\
\hline S. aureus ATCC & MIC & 2.18 & 2.09 & 3.44 & 3.21 & 56.68 & 26.33 \\
\hline 6538 & MBC & 8.76 & 2.09 & 55.08 & 51.28 & 56.68 & 26.33 \\
\hline \multirow[t]{2}{*}{ S. aureus Mu50 } & MIC & 4.37 & 4.18 & 110 & 103 & 227 & 105 \\
\hline & MBC & 17.5 & 16.73 & 110 & 103 & 227 & 211 \\
\hline
\end{tabular}

\begin{tabular}{|c|c|c|c|c|c|c|c|}
\hline \multirow[t]{2}{*}{ Parameter } & \multicolumn{7}{|c|}{ Sophorolipid } \\
\hline & $5 a$ & $5 b$ & $5 c$ & $5 d$ & $12 \mathrm{a}$ & $12 \mathrm{c}$ & $12 d$ \\
\hline$R_{\mathrm{g}}[\mathrm{nm}]$ & $3.1 \pm 0.1$ & $3.3 \pm 0.1$ & $2.9 \pm 0.1$ & $2.6 \pm 0.2$ & $3.4 \pm 0.1$ & $2.7 \pm 0.1$ & $2.1 \pm 0.1$ \\
\hline
\end{tabular}

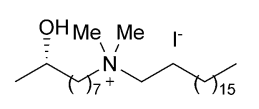

13a

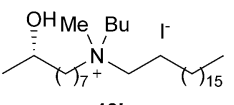

13b
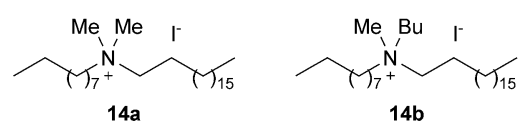

Figure 2. Deglycosylated quaternary ammonium salts 13 and $\mathbf{1 4}$
Table 3. Size and zeta potential $(\xi)$ measurements of solutions prepared at $1.5 \mathrm{~mm}$ after 2 days of hydration without (left) or with (right) DOPE ( $\mathrm{PDI}=$ polydispersity index).

\begin{tabular}{|lcccrcc|} 
Sophorolipid & \multicolumn{3}{c}{ Without DOPE } & \multicolumn{3}{c}{ With DOPE } \\
& size [nm] & PDI & $\zeta[\mathrm{mV}]$ & size [nm] & PDI & $\zeta[\mathrm{mV}]$ \\
\hline 5 a & $186 \pm 110$ & 0.94 & 29.9 & $54 \pm 0.5$ & 0.22 & 49.2 \\
$\mathbf{5}$ b & $275 \pm 49$ & 0.56 & 27.9 & $94 \pm 0.1$ & 0.20 & 40.8 \\
$\mathbf{5}$ c & $261 \pm 9.8$ & 0.38 & 39.6 & $171 \pm 2.0$ & 0.47 & 53.3 \\
$\mathbf{5 d}$ & $189 \pm 4.9$ & 0.25 & 19.2 & $181 \pm 1.2$ & 0.26 & 49.5 \\
$\mathbf{1 2}$ a & $234 \pm 45$ & 0.73 & 40.0 & $103 \pm 0.5$ & 0.28 & 47.4 \\
$\mathbf{1 2} \mathbf{b}$ & $259 \pm 11$ & 0.64 & 33.9 & $86 \pm 0.9$ & 0.24 & 50.1 \\
$\mathbf{1 2}$ c & $141 \pm 3.1$ & 0.39 & 41.0 & $187 \pm 1.3$ & 0.47 & 52.0 \\
$\mathbf{1 2} \mathbf{d}$ & $204 \pm 1.1$ & 0.43 & 43.8 & $235 \pm 4.5$ & 0.50 & 52.2 \\
\hline
\end{tabular}

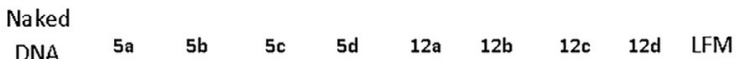
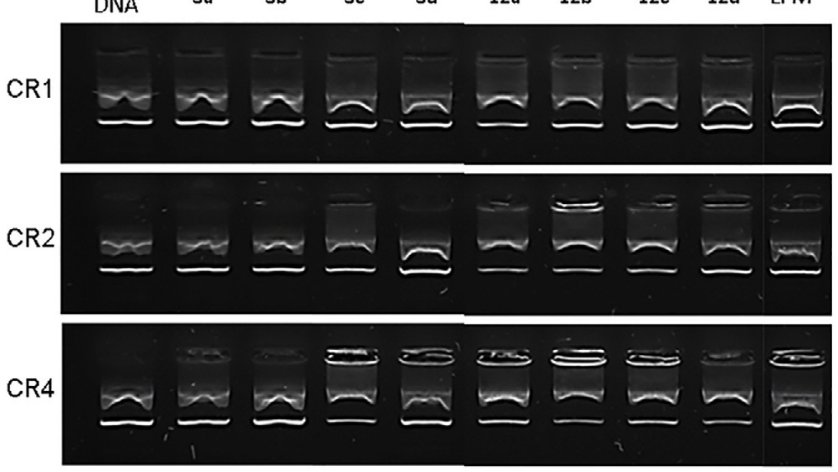

Figure 3. DNA complexation ability of deprotected quaternary ammonium sophorolipids $\mathbf{5}$ and $\mathbf{1 2}$ (formulated with DOPE) as determined by agarose gel retardation assay for different charge ratios. Naked DNA and LFM (Lipofectamine 3000) were used as controls. 


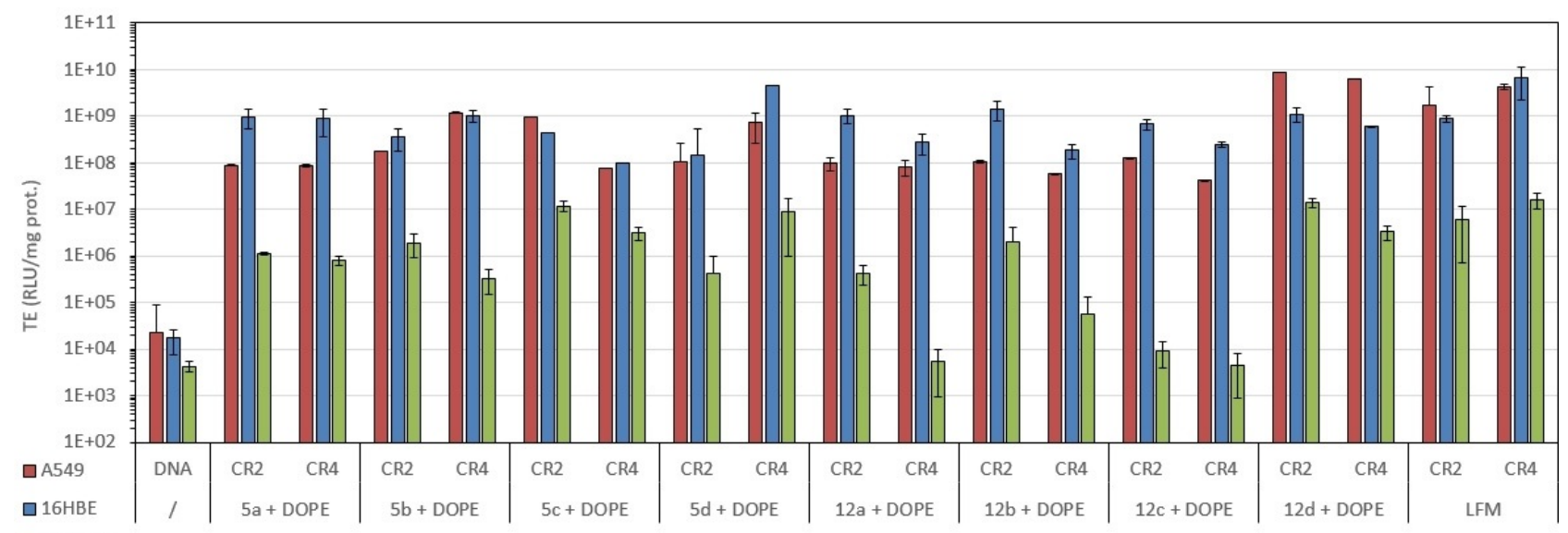

口SKMEL28

Figure 4. Transfection efficacies (TE) of deprotected quaternary ammonium sophorolipids 5 and 12 (formulated with DOPE) on three cell lines (A549, 16HBE, and SKMEL28) by using a luciferase-encoding pDNA. TE are expressed in RLU per mg of proteins $(n=3)$. Lipofectamine (LFM) and naked (uncomplexed) pDNA were used as positive and negative controls, respectively.

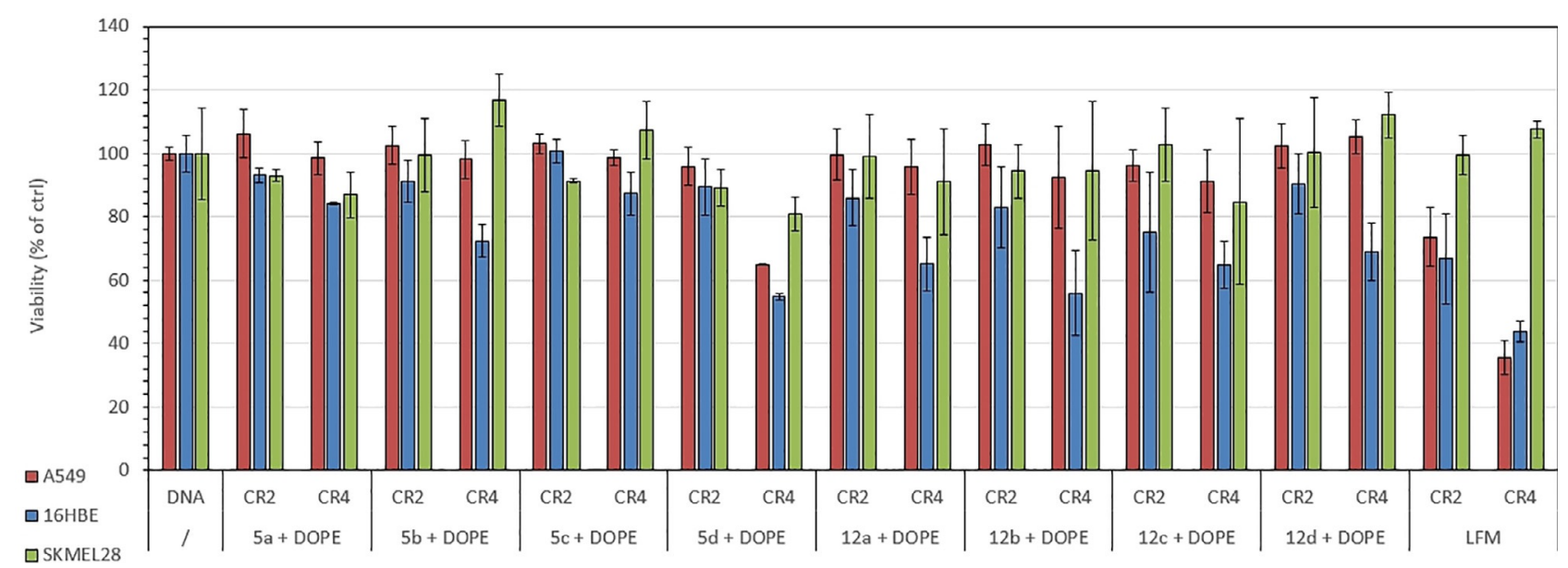

Figure 5. Cell viability determined $48 \mathrm{~h}$ after incubation of the cells with lipoplexes prepared with deprotected quaternary ammonium sophorolipids $\mathbf{5}$ and $\mathbf{1 2}$ (formulated with DOPE). Naked pDNA was used as the negative control. Values are expressed as a percentage of the viability determined with untransfected cells. 


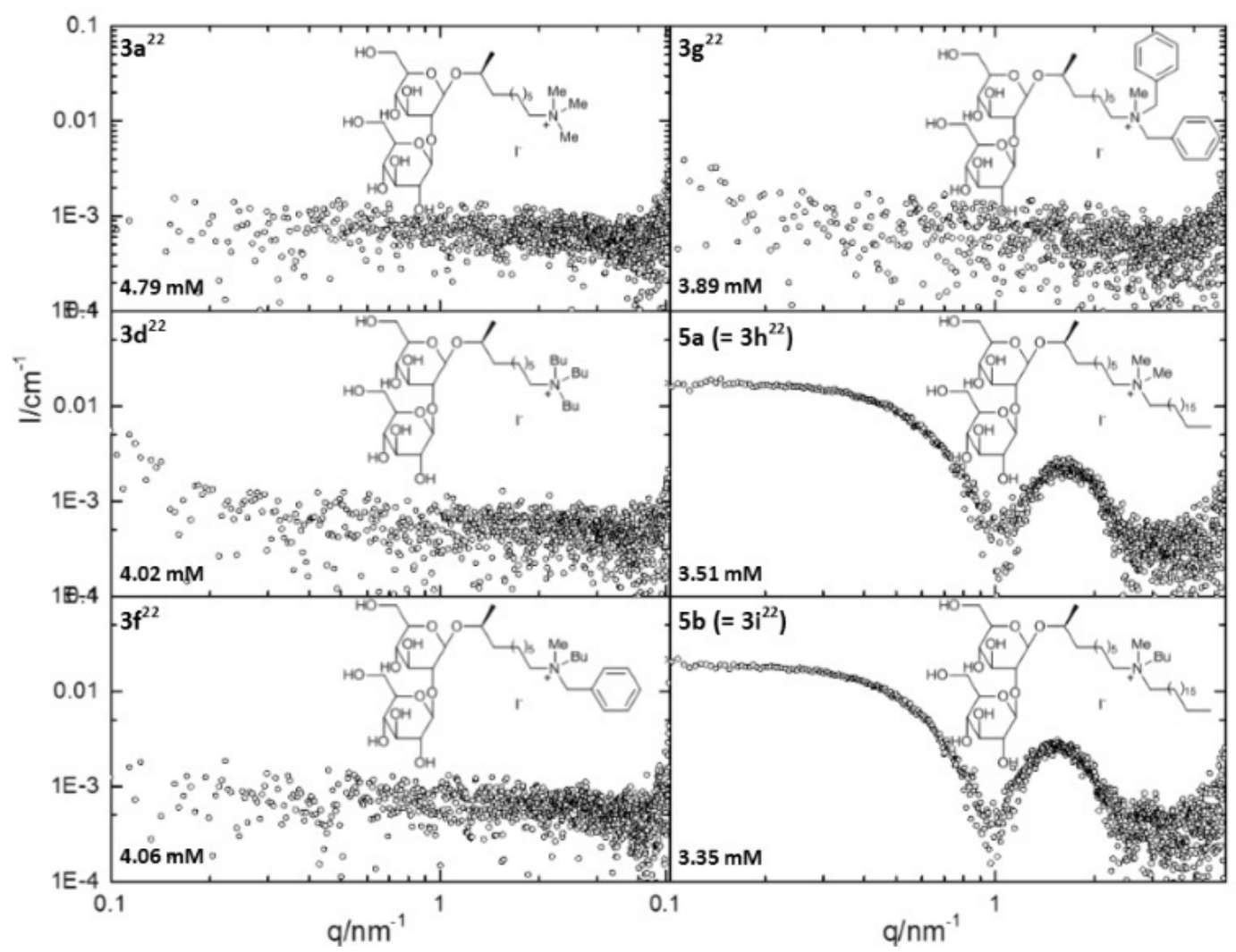

Figure 6. SAXS data of oleic acid-based quaternary ammonium sophorolipids 3 and $\mathbf{5}$ at a concentration of $3.13 \mathrm{mg} \mathrm{mL}^{-1}(=3.35-3.88 \mathrm{~mm})$.

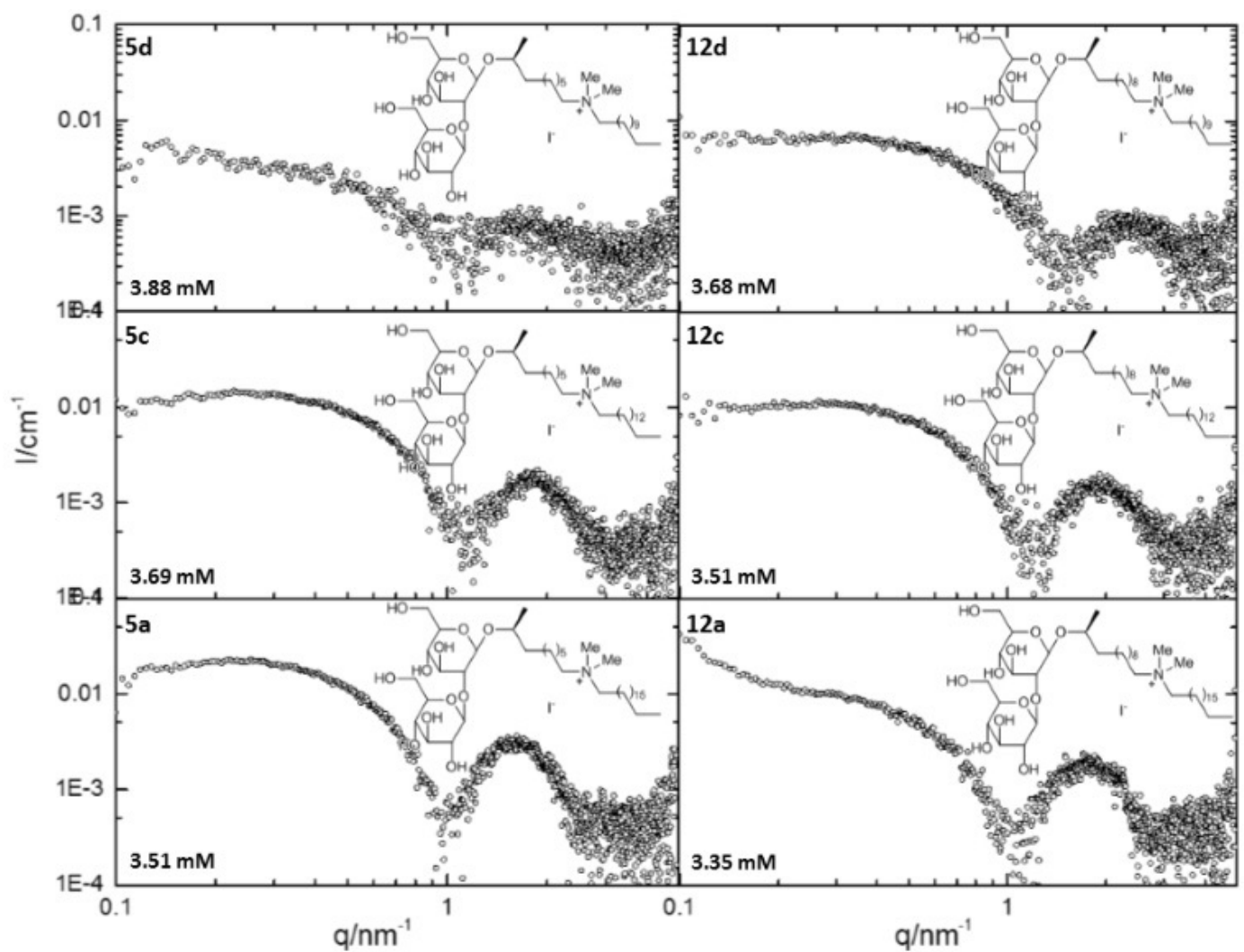

Figure 7. SAXS data of oleic acid-based quaternary ammonium sophorolipids 5 and petroselinic acid-based quaternary ammonium sophorolipids 12 at a concentration of $3.13 \mathrm{mg} \mathrm{mL}^{-1}(=3.35-3.88 \mathrm{mM}$ ). 